by Richard A. Rudey and Porter J. Perkins

Lewis Research Center

Cleveland, Ohio 44135

TECHNICAL PAPER proposed for presentation at International Conference on the Environmental Impact of Aerospace Operations in the High Atmosphere sponsored by the American Institute of Aeronautics and Astronautics and the American Meteorological Society Denver, Colorado, June 11-13, 1973 


\section{MEASUREMENT OF HIGH-AITITUDE AIR QUALITY USING AIRCRAFT}

Richard A. Rudey and Porter J. Perkins

NASA Lewis Research Center, Cleveland, Ohio

\section{Abstract}

The minor atmospheric constituents associated with and affected by aircraft exhaust emissions at altitudes from 6 to $20 \mathrm{~km}$ will be monitored in flight programs presently being implemented. Preliminary in situ data are available from flight tests of dedicated instruments to be used in these programs. A Global Atmospheric Sampling Program using Boeing 747 airliners was determined to be feasible in studies conducted by airlines and airframe companies. Worldwide monitoring in the troposphere and the lower stratosphere is planned. Stratospheric afr sampling on a more local basis w111 be done with a U2 aircraft. Measuring system evaluations and improvements have been required to

等 detect the low background levels.

\section{Introduction}

Various test vehicles are being used for in situ and remote sensing measurements of minor atmospheric constituents. This paper presents and describes several programs currently belng implemented by the National Aeronautics and Space Administration (NASA) which use aircraft as carriers for instrument packages for in situ measurements. These programs are aimed at obtaining air-quality data over various periods of time ranging from minutes (in an aircraft wake) to years (in the ambient environment); over a wide range of altitudes, from 6 to $20 \mathrm{kilometers;} \mathrm{and} \mathrm{over} \mathrm{a} \mathrm{wide}$ variance of global locations.

The continuing debate regarding the impact on the natural ambient enviroment of aircraft operating at high altitudes is continually pointing out the need for data regarding the status of certain minor atmospheric constituents with time and location. Potentially harmful reactions between engine exhaust products and ambient levels of ozone have been demonstrated (ref. 1) in laboratory tests. However, these reactions may be affected by the rates and levels at which these exhaust products are injected and dispersed in the atmosphere. The Department of Transportation (DOT) is currently conducting an investigation called the Climatic Impact Assessment Program (CIAP) which has as its goal the prediction of the potential effect that large fleets of aircraft operating at high altitudes will have on the ambient atmosphere. Some of the more pertinent Information being explored in this program is given in references 2 and 3. This program represents comprehensive look at all aspects of the potential atmospheric impact, but it relies on a Ifmited amount of data taken in the atmosphere and is limited because of a rigorous time schedule terminating in 1974. These 1imitations will certainly be factors in the final assessment arrived at in this program.

The data which are currently being used for the development of atmospheric models that are and will be used to assess aircraft impact, such as in CIAP, are mainly obtained with balloons, rocket sondes, and research aircraft. These data have provided a significant bank of information regarding altitude profiles of atmospheric constituents (refs. 4 and 5) but are limited to local areas of the earth's atmosphere. The use of satellites with remote sensors to observe the earth's stratospheric constituents on a circumferential basis is showing considerable promise also and should provide considerable data in the future. At this time, however, it is apparent that the airplane equipped with dedicated instruments provides a unique capability to obtain data over $a$ widely dispersed area of the globe and to obtain altitude profile data to approximately 20 kilometers. Because of this capability, NASA is currently implementing several high-altitude airquality measurement programs. These programs are aimed at providing both local and widely dispersed data over a long period of time. These data will furnish a data bank that will be made available to both atmospheric scientists and aerospace engineers It is our hope that these data will supply the necessary inputs to determine more accurate atmospheric models, to provide an additional input for determining the potential impact of alrcraft on our enviroment, and to determine which aircraft engine exhaust products are most detrimental to the ambient environment. Reduction of these detrimental exhaust constituents will be the major thrust of aircraft engine pollution reduction research.

This paper describes the programs that are being implemented, discusses the main reasons for utilizing aircraft as instrument carriers, presents some preliminary results of meas urements made with a "breadboard" measurement system, discusses the current limitations of dedicated instruments for making the in situ measurements, and describes an automated system that is planned for application aboard commercial Boeing 747 aircraft for a global sampling effort.

\section{Aircraft as Pollution Source and Monitor}

\section{Pollution Source}

The exhaust constituents which are discharged ty an aircraft engine into the atmosphere are composed of inert substances and unreacted oxygen from the air, products of combustion, oxides of nitrogen produced by heating the air, and elements or compounds derived from sulfur and trace metals present in hydrocarbon fuel. An example of the type and concentration of these constituents for a particular engine operating condition is illustrated in table 1 . The source that produces the individual constituents is also indicated. It is important to note that the particular levels of the constituents shown reflect current aircraft engine technology and are not representative of advanced combustion design technology that will reduce those products affected by the cambustion process.

Of primary interest are those products associated with incomplete combustion such as carbon monoxide ( $\mathrm{CO}$ ), total hydrocarbons ( $\mathrm{THC}$ ), hydrogen 
$\left(\mathrm{H}_{2}\right)$, particulates (smoke), oxides of nitrogen $\left(\mathrm{NO}_{\mathrm{x}}^{2}\right)$, sulfur compounds $\left(\mathrm{SO}_{2}\right.$ and $\left.\mathrm{SO}_{3}\right)$, and trace metals. Many of these products are of considerable concern because of potential interactions with the ambient environinent that can produce a detrimental effect on both low- and high-altitude alr quality. A continual buildup of these constituents over a period of time in either the troposphere or the stratosphere could lead to potential detrimental effects. Hence, they are of considerable interest from an atr-quality-monitoring viewpoint. The discharge of water vapor $\left(\mathrm{H}_{2} \mathrm{O}\right)$, carbon dioxide $\left(\mathrm{CO}_{2}\right)$ and particulates into the ambient enviroment may have an impact on the climate and the weather over a long period of time. Ilence, they too are of considerable interest for monitoring purposes.

Perhaps the most controversial potential effect of aircraft operation in the upper atmosphere is related to the potential interactions between NO and ozone $\left(\mathrm{O}_{3}\right)$ which could result in depletion $\gamma_{f}$ the natural $\mathrm{O}_{3}$ level. It is therefore imperative that $\mathrm{O}_{3}$ also be monitored.

\section{Pollution Monitor}

The reason that the commercial airliner is attractive as a flight vilicle to monitor detrimental constituents of alrcraft exhaust is illustrated in figure 1 . This map related some of the present commercial airline routes to the earth's surface. As is easily observable, a considerable portion of the earth's atmosphere is traversed by commercial alrliners. In most cases these routes are used daily, as a minimu. The North Atlantic route and some of the transcontinental routes have extremely heavy traffic on a 1ess-than-hourly basis. This type of route structure provides a wide variance in locale, as we11 as coverage of both upper troposphere and lower stratosphere, to provide a reasonably comprehensive survey of the globe. This was one of the features which made commercial airline aircraft attractive to NASA as a test vehicle for air-quality monitoring. Furthermore, these aircraft would monftor the air quality in the flight corridors where the majority of the engine exhaust products are discharged and where potential detrimental effects could be the greatest.

In addition to the commercial airline aircraft, other aircraft can also be used on a more local basis to obtain data for the "off-route" areas and to provide data at the altitudes at which the commercial airlines do not fly. This information is of interest to determine the contribution of natural effects, such as thunderstorms, as well as the manmede contribution to the ambient environment.

\section{Current NASA Aircraft Programs}

The basic aircraft programs being implemented by NASA which involve atmospheric sampling use aircraft in current service. These programs provide a wide variety of capabilities in terms of their goals and are unique in their objectives. However, the data gathered will be interrelated for overall analysis.

\section{Global Atmospheric Sampling Program}

The Globel Atmospheric Sampling Program (GASP) has as its objectives (1) the determination and documentation of worldwide concentrations of atmospheric constituents associated with gaseous and particulate pollutants in the troposphere and the lower stratosphere (up to $12 \mathrm{~km}$ ) over a period of several years and (2) the determination of the contribution of jet aircraft to possible atmospheric contanination during this time period. In order to accomplish these objectives, a program study was performed to determine the most viable method of approach. This study led to the selection of a plan to utilize commercial jet airliners because of their global route structure (Fig. 1) and because of their frequency of travel, both of which would allow the accumulation of a large amount of widely dispersed data. A timetable to implement and conduct the program was selected, and a data acquisition period of from 3 to 5 years was chosen. A considerable amount of preparatory work in instrument selection, system design, preliminary flight tests, and overall program feasibility based on using in-service commercial airplanes was necessary prior to the indiation of this program. The results of these efforts are discussed in detail in subsequent sections of this paper. The program is being managed by the NASA Lewis Research Center.

\section{Stratospheric Air Sampling Program}

The Stratospheric AIr Samp1ing Program (SASP) has as its objectives (1) the determination of the background levels of various minor atmos pheric constituents in the 12- to 20-kilometer altitude region, (2) the determination of the contribution of both natural and manmade perturbations to stratospheric air quality on a somewhat local basis, and (3) provision of data for stratospheric mixing models to validate and/or revise analytical techniques. This program is being managed out of the NASA Ames Research Center and utilizes $\mathrm{U} 2$ aircraft as the measurement system carrler. This aircraft is shown in figure 2. The type of instrumentation to be used in this program is similar to that being considered for the GASP program, with the exception that the equipment need not be as critically designed for automated and long-term operation. However, the concentrations of some of the detrimental exhaust constituents to be measured may be somewhat different; and, hence, the sensitivity requirements might vary to some extent. A detailed description of this program and the measuring system is given in reference 2. No further information on this program is given in this paper.

\section{Stratospheric Jet Wake Experiment}

The Stratospheric Jet Wake Experiment (SJWE), which is in its early stages, is aimed at measuring the dispersion and dissipation of pollutants in the jet wake of an aircraft. This program is being managed by the NASA Ames Research Center, with principal assistance from the NASA Flight Research Center and additional assistance from the Lewis and Langley Research Centers. Part of this effort is concerned with determining the feasibility of using dedicated instruments for making in-situ measurements within a jet wake over a period of time in an attempt to assess the poliutant dispersion and potential reactions that may occur between the engine exhaust products and the minor constituents in the ambient atmosphere. Several preliminary flights have been conducted 
us Ing the NASA Ames Reseacch center CV-990 airplane instrmented with several types of in situ measurement systems as the sensing atrcraft and QR-57 and $F-104$ as the emisston source aircraft, The CV-990was flown into the wake of the source atrcraft and vartous constituents were measured. The teats were conducted in the troposphere with in the near field of the source aircraft $(0.6-$ to $10-\mathrm{km}$ separation). One of these flights along with sotae preliminary measurements made within the wake of the source aircraft using several prototype instruments for the GASP system, is described in a subsequent section of this paper.

\section{Primary Constituents and Candidate} Measuring Techniques

The atmospheric pollutants that are a part of the exhaust emisstons of iet engines (as descrlbed previously) are and will be measured in situ by instrumented aireraft. The minor atmospheric constituents that may be modified by reacting with these emissions will also be measured. A complete list of these exhaust and atmospheric constituents could be made very long; however, they must be confined to those which can be readily measured from an aircraft test platform. At the present time, easily measurable constituents include $O_{3}$, water vapor, and particle concentrations and size distributions above 0.2 micrometer in dlaneter. The identity and total mass of airborne particles can also be obtained by filter and impactor techniques. Instruments are also avallable to measure $\mathrm{CO}$, NOX $\mathrm{CO}_{2}$, and particle concentrations and size distrir butions below 0.2 micrometer (Aicken nuclei). More care must be used, however, to make these measurements.

\section{Background Levels and Instrument Capabilities}

The aparoximate ranges of gaseous and particulate atmospheric pollutants at altitude and ground level (nonurban) are given in flgure 3. This informatton was provtded by or. John Milier of the National Oceanic and Atmospheric Administration (NOAA) from review of avallable data gathered by balloons, rockets, and aircraft research flights. The capability of certain avallable instrument measurement techriques is also shown in this figure. These avajlable techniques include only those considered as candidates for the commercial airline installations discussed later in this paper. This application imposes restrictions on measurement techniques that would not necessarily apply to laboratory equipment.

The figure shows that some pollutant concentrations are below the range of candidate tnstrunents avallable at the time of this study. The atmospheric constituent concentrations that were measured include $0_{3}$, water, and particulates greater than $0.2 \mathrm{micrometer}$ in diameter. The

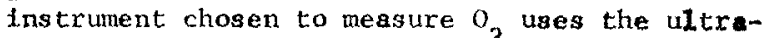
violet absorption principle. The water vapor measurement is based on aluminum oxide adsorption. Both instruments can cover the expected background levels. The measurement of particle concentration and siae distribution can be obtalned if the particle diameter is above 0.2 micrometer.
Methods have been demanstrated or proposed to improve the sensitivity of the candidate measuring techniques for $\mathrm{CO}, \mathrm{NO}$, and $\mathrm{CO}_{2}$. Some development effort and time will be necessary before these improvements can be evaluated and subsequently utilized for routine aicraft measurenents. Elgure $3(a)$ shows that the low range of the $c 0$ measurement technique must be extended about an order of magnitude. The four commexcially available chemiluminescence Instrunents to measure No appear to have limited capability to measure this constituent at altutude. Recent research instrument developments to improve the low range of the chemiluminescent measurement by about two orders of magnitude appoar promising. The measurement problem for $\mathrm{CO}_{2}$ (non dispersive infrared, or NDIR) is unique in that the candidate instrunent will cover the range but lacks the resolution to detect the relatively sinall concentration variations that must be known to detect any pollution effects. The candidate instruments for measuring $\mathrm{SO}_{2}$ require wore than an order of magnitude extension at the low end of the range to detect this pollutant. No methods have been investigated to inprove the sensitivity of these candidate measuring techniques. Instruments suitable for afrcraft installations which will measure total hydrocacbons (THC) and ammonia $\left(\mathrm{NH}_{3}\right)$ testimated background levels are not currently avaliable.

Measuring particles below 0.2 micrometer in diameter (Aitken nuclei) requires a condensation nuclei counter. The counters under cansiderstion appear to cover most of the expected range of nuclet concentrations at alrliner flight altitude (fig. 3(b)). A basic probletn in the use of condensation nuclei counters at these altitudes is the low ambient pressure of the air sample. The operating principle requires expansion of the ir for the condensation process. The low-pressure air must, therefore, be intelally pressurized to about 1 atmosphere prior to expanston. This also allows the basic calibrations of the instrument, which are made at 1 atmosphere, to be used. Care must be taken in pressurizing the air to avold changing the nuclei concentrations. Con pression by pumping tends to drive the nuclei together. A procedure being evaluated is to pressurize the air sample in a chamber by charging it with the pressurized afrcraft cabin atr which has been passed through a filter to remove all nuclei and then introducing the sample into the counter. The nuclei concentrations are not expected to be altered by this technique, which will be flight tested as part of the overall program.

\section{Experimental Flight Test Evaluations}

\section{Experimental System}

As part of the implementation of the Global Atmospheric Smpling and Stratospheric Air Sampling Programs, selected instruments hove been flight tested on the NASA CV-990 aircraft. This afrcraft, with its felxibility for installation of laboratorytype equipment and 1 ts data acquisition systems (ref. 2), provided an ideal facility for atmospheric studies and evaluations of atmospheric measurement instruments. Figure 4 shows the location of several external probes on the $\mathrm{CV}-990$ for acquiring outside air samples. The many 
measuring systems that were used concurrenty on flighes required several probes of sifghtly different configurations. These are shown in the forward part of the aircraft (figure 4).

An air sample flow systen from the external probes into the instruments being evaluated is shown In figure 5. Some measurements, such as $\mathrm{O}_{3}$, used the outside air sample pressurlzed to I atmosplete by a diaphragrn-type pump. Pressureregulating valves held the pressure at 1 atmosphere with inlet pressures (including the dynamic pressure) varying from 0.68 to 0.25 atmosphere ( 6 to $12 \mathrm{~km})$. Other instruments, such as the particle counter, need an air sample as undisturbed as possible. In order to accomplish this, air is ducted as directly as possible (1argeradius bends) Into the sensor unit. Separate tubing materials are necessary for these air sample 1ines. Teflon surfaces are required to minimize the destruction of $\mathrm{O}_{3}$. However, particles will cling to Teflon and, therefore, stainless steel must be used in such systems as the particle counter.

\section{Instruments Flight Tested}

Table 2 lists many of the instrument operating principles that were evaluated during recent CV -990 flight tests to measure several minor atmospheric constituents.

Four methods for measurting $O_{3}$ opexated satisfactorily. Chemiluminescence using ethylene gave fast response times but presents a potential fire hazard from the ethylene, Uttraviolet absorption (zero reference system) displayed a 20-second step time delay. A second derivative spectroscopy unit was used to scan five constituents, resulting in 16 minute intervals between the measurements of a given constituent. The specific-wavelength scan period to observe a particular constituent repeatedly took 5 minutes. The electrochemical technique showed a response time of about 30 seconds.

Two methods for measuring $C O$ displayed limited capability. The fluorescent nondispersive infrared (NDTR) technique lacked sensitivity to detect concentrations in nonurban aceas and above ground level, as did the chemical-optical technique (hot mercuric oxide). A laboratory-modified version of this technique demonstrated sufficient sensitivity for detection of low concentrations but presented some calibration problems and difficulties in flight.

The NDIR technique for measuring $\mathrm{CO}$ presented a resolution problem (as noted earlier). Also, sensitivity to ribration and aircraft maneuvers, as well as zero and span drift, became apparent during flight.

Tests of the aluminum oxide adsorption hygrometer are discussed by Edward Hilsenrath in another paper presented at this meeting.

Other instrument operating principles were examined to a very limited extent. Initial difficulties were encountered and not resolved because of the limited time allocated to the flight periods. More testing time is needed to obtain better evaluations. In general, it can be stated that: improvements, and in some cases, development of many of the instruments are required to detect the low-level concentrations of the varlous constituents in the upper atmosphere and to perform under the pressure and vibration condtions encourtered during operation in aircraft.

\section{Preliminary Results}

Comparison of the two $\mathrm{O}_{3}$ measurement principles and the effect of cabin pressuriration and air sample pressurization on $\mathrm{O}_{3}$ levels were obtained on several of the CV-990 flight tests. These data are shown in figure 6. Both the ultraviolet absorption and the electrochemical (KI) measurement techniques show good agreement when the air sample is pressurized to 1 atmos phere by a diaphragm pump. The error due to loss of $\mathrm{O}_{3}$ in thits system proved to be small. Laboratory tests showed $\mathrm{O}_{3}$ losses through the complete plumbing system, including the pump and the Teflon 1 ines, of less than 20 percent for stay times in the system of about 20 seconds. Flight tests also showed small losses of $o_{3}$, in the pressurized system. Eigure 7 compares data points for an instrument connected direct $1 \mathrm{y}$ to the low-pressure outside air to those from an instrument connected to the pressurizing system. Good agreement is shown between the pressurized and unpressurized systems. The outside sensing instrument required encasement in a container vented to outside pressure.

During one flight, the electrochemical instrument was detached from the outside air line and set up to measure the $\mathrm{O}_{3}$ level in the pressurized cabin of the CV-990. With outside $\mathrm{O}_{3}$ levels around 50 to 80 parts per billion, the amount of $\mathrm{O}_{3}$ in the cabin was about 50 to 60 percent less, as shown in figure 6 . The inlet to the instrument that was measuring cabin $\mathrm{O}_{3}$ was about 8 feet from the cabin air inlet duct.

\section{Global Atmospheric Sampling Program}

The GASP program is presently in the implementation phase for installing the first system on an alrline aircraft. The initial phase was a feasibility study conducted by airlines (American, United, and Trans World) and the Boeing Company. The concept was found to be both technically feasible and acceptable to the airlines. The study resulted in the selection of the Boeing 747 afrliner to carry the equipment. This selection was based on (1) the avallable nonrevenue space on aircraft, (2) the provision of global coverage, and (3) the avallability of an inertial navigation system (INS) and an air data system (ADS) to pinpoint time and location of the air constituent measurements.

The location of the air inlet probe and measuring equipment on the Boeing 747 is illustrated in figure 8 . The probe is mounted well forward on the under part of the fuselage to collect an undisturbed air sample and to be free of groundhanding interference. The sample is ducted back about 15 feet to the location of the measuring system, which is mounted on special racks on the left side of the aircraft forward of the existing avionics rack. 
Description of System

The CASP system can be best described by dividing it into lour elemental or functional categories: (1) the inlet probe with a sealing cap for closing ofe the airflow below sampling altitude: (2) the air sample ducting and pressurization and low control units; (3) the air constitwent measuring tnstruments; and (4) the data acquistefon, managenent, and control units. The first three elements are essentialiy the complete air salle flow system. This is shown schematically in flgure 9. Air from the controlled inlet probe will be ducted through a filter unit for particle identification (for later laboratory analysis). A separate tube from the same inlet supplies a sample to the suall particle and nuclei counters. Flow for the gas analyzer instruments goes through another tube to a punp and a pressure regulation system and into the instrument intake manifold. A bypass of the pressurization system is included for those measuring devices which do not require a pressurized air sample. The measuring devices are connected between inlet and outlet nanifolds which are held at a constant differential pressure by pressure regulators. The exhaust from the outlet manifold is discharged to the outside through a vent in the nose gear wheel well of the Boeing 747 aircraft.

A calibration cycle will be necessary during flight for some instruments. A number of solenoid valves are used to shut off the outside airflow, to provide a supply of zero gas, and to supply a calibration gas for checking the span of each instrument.

The fourth element in the GASP system is the dat acquisition and control system, as shown In figure 10. Under the constraints which require the complete system to operate automatically with no attention by the airline flight crew other than emergency procedures, the contro1. inputs for the entire flight must be automatically programmed. Control signals to the system will be generated as functions of time, pressure altitude, and interfaces with other aircraft systems by Data Management and Contro1 Unit. This unit contains the necessary logic (timing and sequencing) to perform all data management and control functions for the entire air sample system. All data from the air constituent measuring instruments, related data on system operation, and data fron the aircraft systems are channeled through the Flight Data Acquisition Unit. This unit is a standard ARINC 573 flight recording unit familiar to many airline operators. The output of this unit is properly conditioned for recording on a standard serlal digital flight recorder using magnetic tape.

\section{Constraints on System}

The airline feasibility study defined some ground rules that should be imposed on the instrumentation system. The reasoning was that the systems would be installed on scheduled commercial aircraft being operated for revenue and, therefore, should not interfere with the nomal airline operations. The specific constraints are as follows:
(1) No revenue space would be taken from exther the passenger compartment or the cargo hold.

(2) No afr crew duties would be imposed beyond operation of an on/off switch.

(3) Limited servicing and maintenance would be performed on an noninterference basis.

(4) FAA Supplemental-Type Certification will be required.

The finalized design and Implementation of the final system will necessarily require that these constralnts be adhered to.

\section{Aircraft Jet Wake Measurements}

As part of a study being conducted to assess the problens and feasibility of locating and sampling engine exhaust products in an alrcraft wake, a rendezvous flight between the Ames Research Center's CV-990 and the Flight Research Center's F-104 was conducted over the coast of southern California. The flight experiment was conducted at an altitude of approximately 11 kilometers and a flight speed of approximately Mach 0.8. The main purposes of this experiment were to determine the ability of the sensing aircraft (CV-990) to find and remain in the F-104 wake and to determine the ability of the onboard measurement systems to detect concentration levels of certain constituents in the exhaust plume.

The F-104 is it rendezvoused with the CV-990 is shown in figure 11. After initial contact was made, the $\mathrm{F} \sim 104$ accelerated away from the sensing aircraft and generated the exhaust plume that was to be monitored. Because of favorable atmospheric conditions a clearly visible contrail was produced by the source aircraft. The contrail formed during the actual flight is shown in figure 12. This visible contrail was used to locate and position the sensing afrcraft in the wake. The aircraft separation distance as measured by radar was varied from approximately 0.6 to $10 \mathrm{kilometers.} \mathrm{Due} \mathrm{to} \mathrm{the} \mathrm{turbulence} \mathrm{in}$ the wake, the sensing ircraft was intermittently pitched in and out of the wake. Hence, the gas samples being sensed by the onboard instruments were constantly varying.

The variation of some of the exhaust constituents as a function of time, aircraft separation, and engine operation with afterburning are shown in figure 13. The principal gaseous constituents measured were $\mathrm{CO}, \mathrm{NO}_{\mathrm{x}}$, and $\mathrm{O}_{3}$. The No was measured with chemiluminescence monitor with a sensitivity of 10 parts per billion volume, the $C O$ with a fluorescent NDIR monitor with a sensitivity of 200 parts per billion volume, and the $\mathrm{O}_{3}$ with an ultraviolet absarption monitor with a sensitivity of 3 parts per bilion volume. The decreases in both $\mathrm{CO}$ and NO levels as aircraft separation distance is increased shows the relative mixing and dispersion of the engine exhaust products with distance (time). Also the high values of co observed during the encounter illustrate the inefficiency of combustion typical of jet engine afterburners. No discernible changes in $\mathrm{O}_{3}$ levels could be attributed to aircraft separation distance or to measurements taken within or out of the wake. (The separation distances can be 
comverted into tim.s, Exm pollutant injection to measurement, varyine from approximately 0.2 to 1.0 sucond.) Hence, no reaction between the No in the exhaust and the ambient 0 would be expected, nor was any observed. $3_{\text {rhis type of }}$ prelininary data can be used as en input into near-rield jet wake mixing models such as the one described in reference 6 .

\section{Concluding Remarks}

Programs to measure certain minor atmospheric constifucuts in situ by using aircraft as carriers of ledicated instruments are currently being implemented by MASA. These programs provide a means of obtaining atmospheric data over a wide variance of altitudes and localities and are aimed at obtalning information regarding the effects of both natural and manmade (alrcraft exhaust pollutants) perturbations on the ambient environment. 'These data will be obtained over a period of years and should provide atmospheric scientists with valuable data regarding the status of the anbient environment of both the upper troposphere and the stratosphere (6m to $20-\mathrm{km}$ altitudes). Continuous global monitoring of the 6 - to $13-\mathrm{km}$ altitude regime will be provided by commercial scheduled airliners.

Limitations in sensitivity of presently available dedicated instruments will have an impact on the type and qualtty of initially obtained data. Accurate measurements of $\mathrm{O}_{3}$, water vapor, and the size, distribution, and composition of particulates are possible with ninor modifications to existing instruments. Laboratory-lype linstrunents are capable of measuring $\mathrm{NO}_{\mathrm{X}}, \mathrm{CO}, \mathrm{CO}_{2}$, and THC: but these instruments are not suffic iently developed for use on commercial airliners at the present time.

Improvements in Instrument sensitivity and operating principles to provide acceptable automated gircraft instruments is possible and should be developed in the near future. When these instruments are made available, they will be factored into the afrcraft programs currently being implemented.

The data to be provided by the aircraft sensing programs described herein will provide an important data bank until remote sensing systems and velicles can be developed and utilized to provide a continuous and complete atmospheric monitaring network.

\section{RERERENCES}

1. Johnston, H., "Reduction of Stratospheric Ozone by Nitrogen Oxide Catalysts from Supersontc Transport Exhaust," Science Vol. 173, No. 3996, Aug. 6, 1971, pp. 517522.

2. Barrington, A. E., "C1imatic Impact Assess ment Program. Proceedings of the Survey Conference, February 15-16, 1972," DoT-TSC OST-72-13, Sept. 1972, Transportation Systems Center, Cambridge, Massachusetts.

3. Grobecker, A. I., "Assessment of Climatic Changes Due to Flights in the Stratosphere," Paper 72-658, June 1972, AIAA, New York, N.Y.

4. Heath, D. F., Hilsenrath, E., Krueger, A.J., Nordberg, W., Prabhakara, C., and Theon, J. C., "Observations of the Global structure of the Stratosphere and Mesosphere with Sounding Rockets and with Remote Sensing Techniques for Satellites," TM X-66044, 1972, NASA, Greenbe1t, Md.

5. Rosen, J., "Sirnultaneous Dust and Ozone Soundings Over North and Central Amertca." Journal of Geophysical Research, Vol. 73, No. 2, Jan. 15, 1968, pp 479-486.

6. Holdeman, J. D., "An Analytical Mode1 for the Dispersion of Jet Englne Exhaust in Flight," Proposed NASA Techntcal Memorandum. 
TABLE 1. - ENGINE EXHAUST CONSTITUENTS

[FUEL IS COMMERCIAL JET A-I KEROSENE; THE OVERALL FUEL-AIR RATIO IS 0.014.]

\begin{tabular}{|c|c|c|}
\hline CONSTITUENTS & SOURCE & $\begin{array}{c}\text { ESTIMATED } \\
\text { CONCENTRATION }\end{array}$ \\
\hline $\begin{array}{l}\mathrm{N}_{2} \\
\mathrm{O}_{2} \\
\mathrm{~A}\end{array}$ & $\begin{array}{l}\text { AlR } \\
\text { AIR } \\
\text { AIR }\end{array}$ & $\begin{array}{l}77 \% \text { (VOL) } \\
16.6 \% \text { (VOL) } \\
0.9 \% \text { (VOL) }\end{array}$ \\
\hline $\begin{array}{l}\mathrm{H}_{2} \mathrm{O} \\
\mathrm{CO}_{2}\end{array}$ & $\begin{array}{l}\text { EFF COMBUSTION } \\
\text { EFF COMBUSTION }\end{array}$ & $\begin{array}{l}2.7 \% \text { (VOL) } \\
2.8 \% \text { (VOL) }\end{array}$ \\
\hline $\begin{array}{l}\text { CO } \\
\text { UNBURNED HC } \\
\text { PARTIALLY OXIDIZED HC } \\
\mathrm{H}_{2} \\
\text { SMOKE (PARTICULATES) }\end{array}$ & $\begin{array}{l}\text { INEFF COMBUSTION } \\
\text { INEFF COMBUSTION } \\
\text { INEFF COMBUSTION } \\
\text { INEFF COMBUSTION } \\
\text { INEFF COMBUSTION }\end{array}$ & $\begin{array}{l}\text { 10-50 PPM } \\
\text { 5-25 PPMC } \\
\text { 5-50 PPM } \\
0.4-50 \text { PPM (MASS) }\end{array}$ \\
\hline $\mathrm{NO}, \mathrm{NO}_{2}$ & HEATING OF AIR & 50-400 PPM \\
\hline $\begin{array}{l}\mathrm{SO}_{2}, \mathrm{SO}_{3} \\
\text { TRÄCE METALS }\end{array}$ & $\begin{array}{l}\text { FUEL } \\
\text { FUEL }\end{array}$ & $\begin{array}{l}\text { 1-10 PPM } \\
\text { 5-20 PPB }\end{array}$ \\
\hline
\end{tabular}

TABLE 2. - INSTRUMENT OPERATING PRINCIPLES EVALUATED

\begin{tabular}{|c|c|c|}
\hline $\begin{array}{c}\text { ATM } \\
\text { CONSTITUENT }\end{array}$ & $\begin{array}{l}\text { SENS ITIVITY, } \\
\text { PPB }\end{array}$ & OPERATING PRINCIPLE \\
\hline $\mathrm{O}_{3}$ & 1 & CHEMILUMINESCENCE $\left(\mathrm{C}_{2} \mathrm{H}_{4}\right)$ \\
\hline $\mathrm{O}_{3}$ & 3 & $\begin{array}{l}\text { UV ABSORPTION } \\
\text { (ZERO REFERENCE SYSTEM) }\end{array}$ \\
\hline $\mathrm{O}_{3}$ & 10 & $\begin{array}{l}\text { UV ABSORPTION } \\
\text { (2ND DERIVATIVE UV SPECTROSCOPY) }\end{array}$ \\
\hline $\mathrm{CO}$ & 5 & ELECTROCHEMICAL (KI) \\
\hline $\mathrm{CO}$ & 200 & CHEMICAL-OPTICAL \\
\hline $\mathrm{CO}$ & 10 & CHEMICAL-OPTICAL (MODIFIED) \\
\hline $\mathrm{CO}$ & 200 & FLUORESCENT NDIR \\
\hline $\mathrm{CO}_{2}$ & $10^{3}$ & NDIR \\
\hline $\mathrm{H}_{2} \mathrm{O}$ & $10^{3}$ & AI OXIDE ADSORPTION \\
\hline $\begin{array}{l}\mathrm{NO}_{\mathrm{x}} \\
\mathrm{NO}_{\mathrm{X}}\end{array}$ & .3 & $\begin{array}{l}\text { CHEMILUMINESCENCE } \\
\text { CHEMILUMINESCENCE (MODIFIED) }\end{array}$ \\
\hline
\end{tabular}




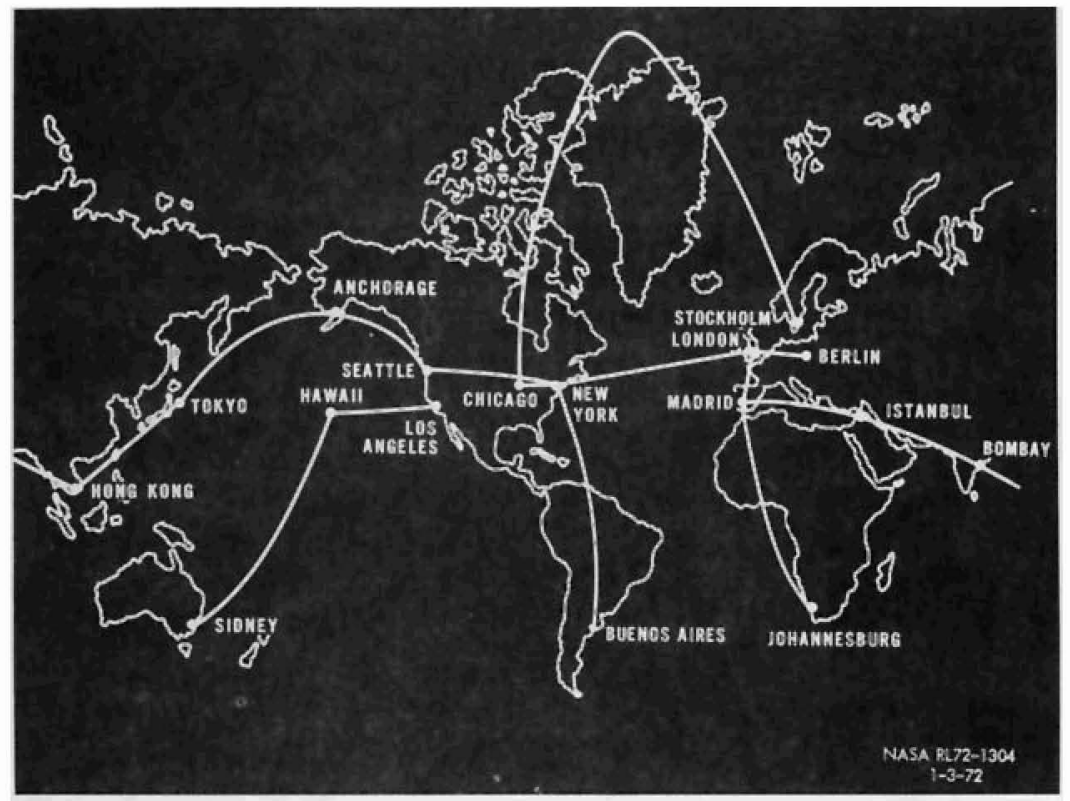

Figure 1. - Global atmosphere sampling proposed routes.

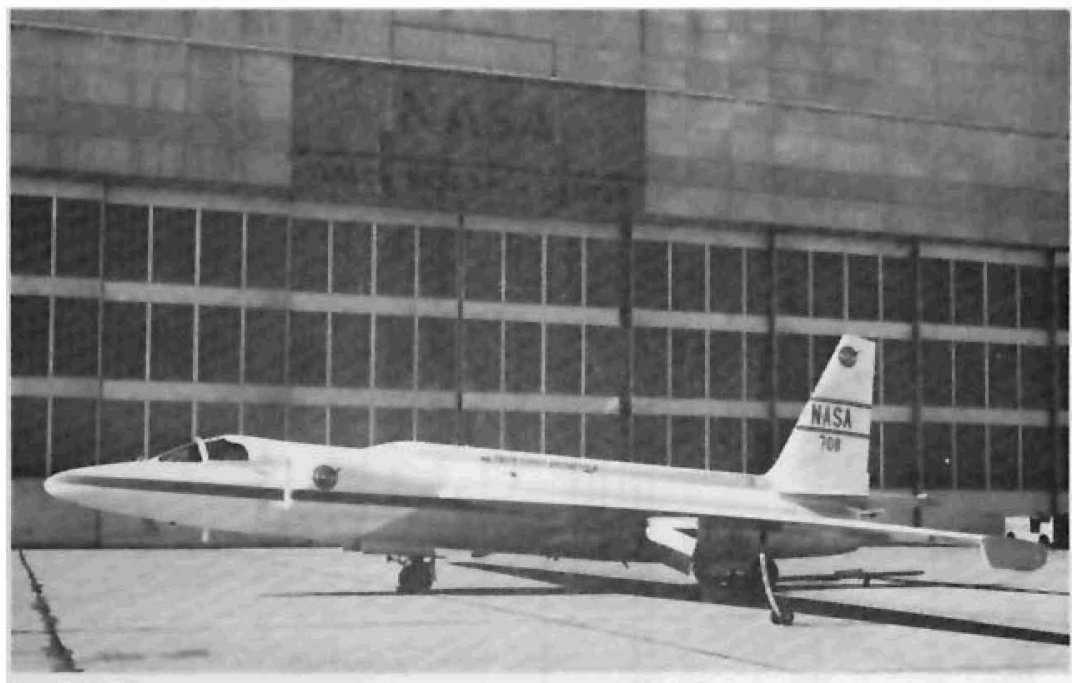

Figure 2. - U2 aircraft used for stratospheric air quality measurements. 


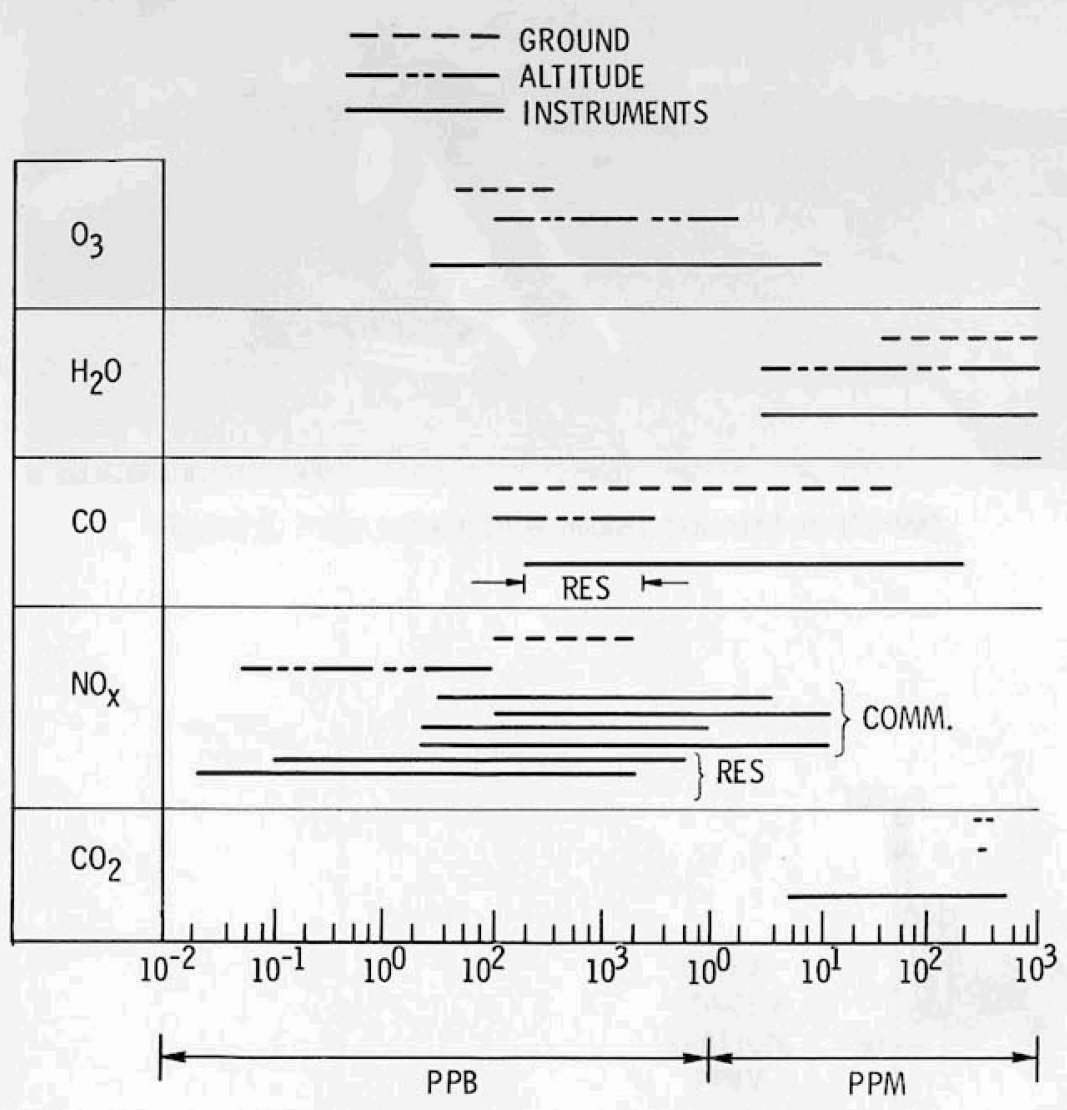

(a) GASEOUS ATMOSPHERIC POLLUTANTS.

Figure 3. - Ranges of particle concentrations and capabilities of candidate instruments.
- - - GROUND

ALTITUDE
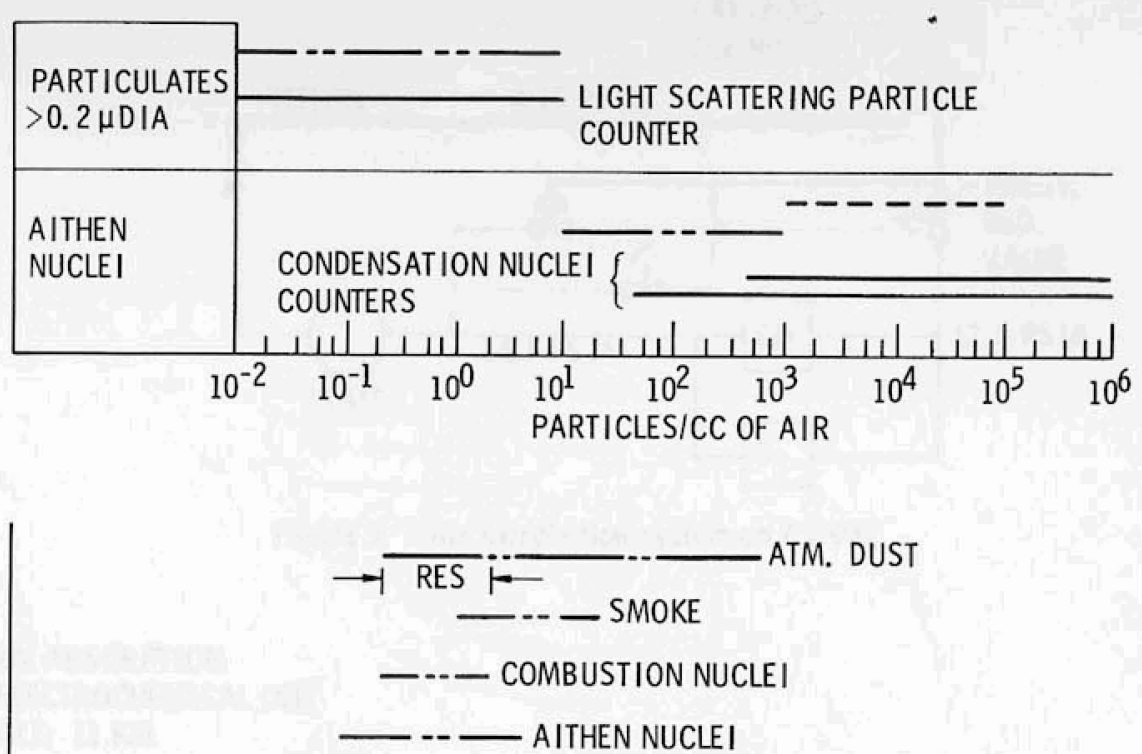

LIGHT SCATTERING PARTICLE COUNTER CONDENSATION NUCLEI COUNTER

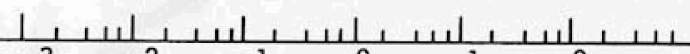
$\begin{array}{llllll}10^{-3} & 10^{-2} & 10^{-1} & 10^{0} & 10^{1} & 10^{2}\end{array}$ PARTICLE DIAMETER, MICROMETERS

(b) PARTICULATE ATMOSPHERIC POLLUTANTS

Figure 3. - Concluded. 


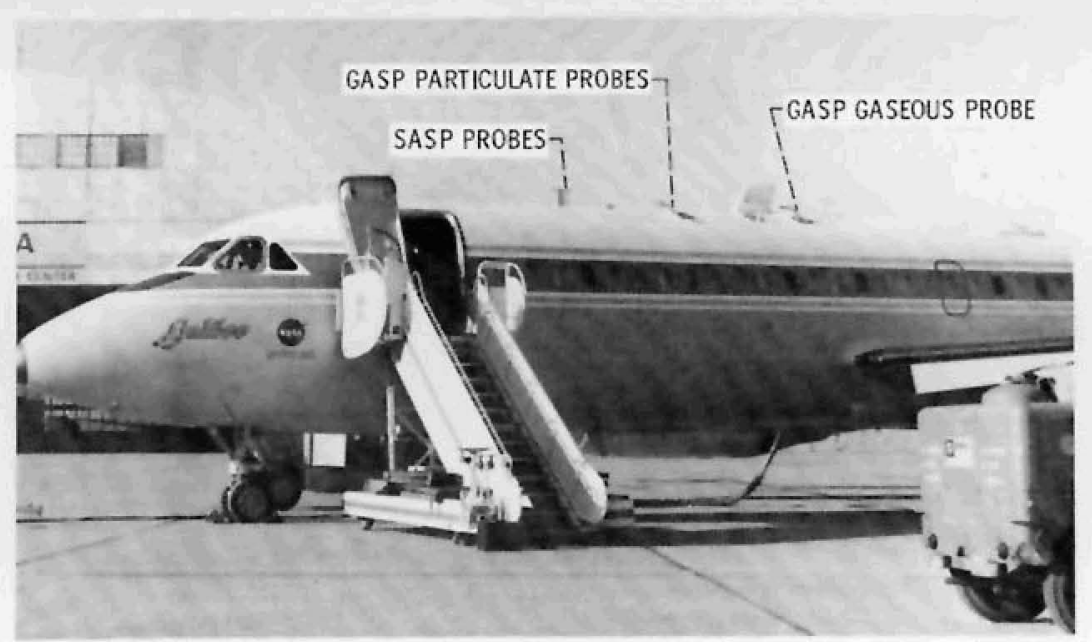

Figure 4. - Air sample inlet probes mounted on CV-990.

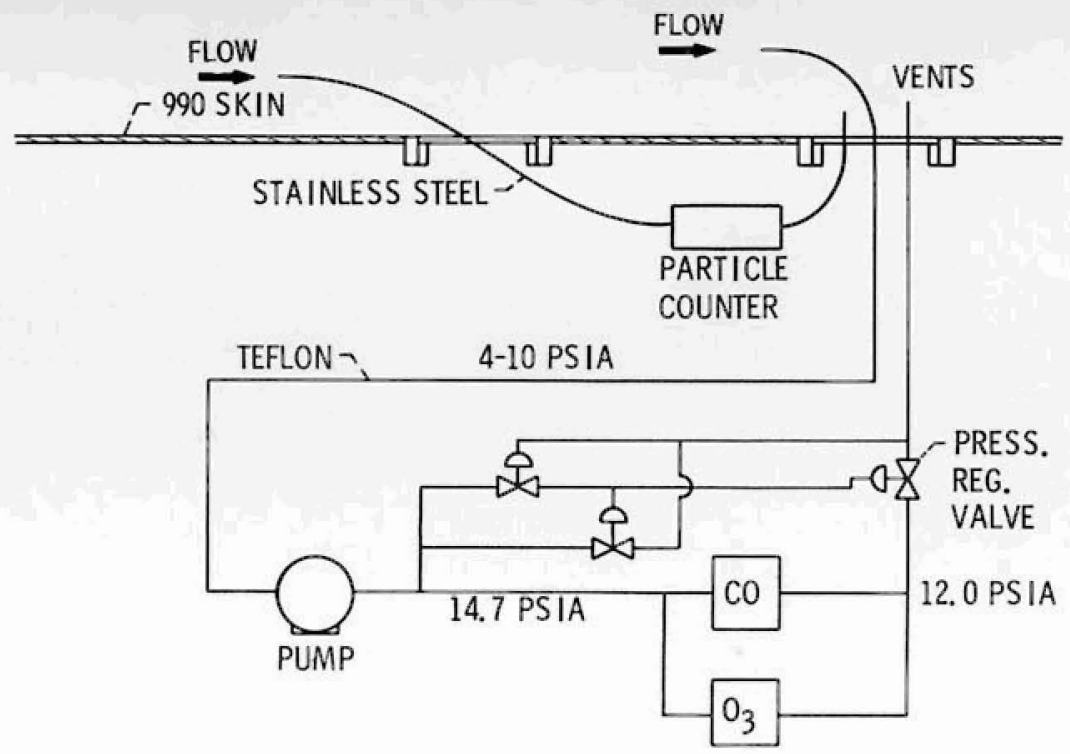

Figure 5. - Air sample flow system on CV 990.

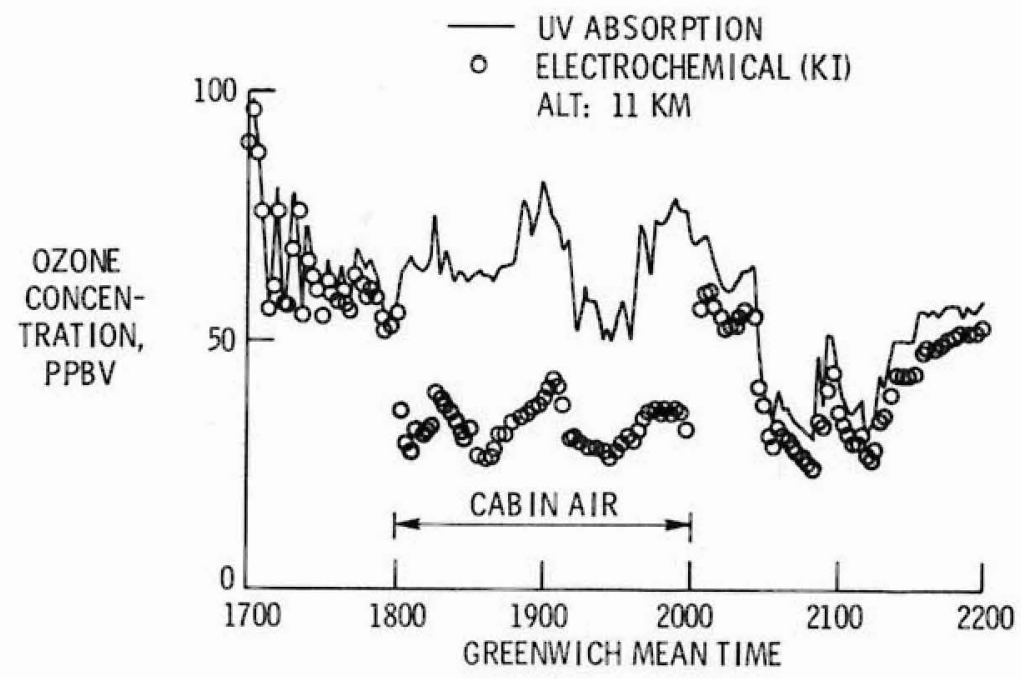

Figure 6. - Comparison of ozone measurement principles and effect of cabin pressurization on ozone level. 

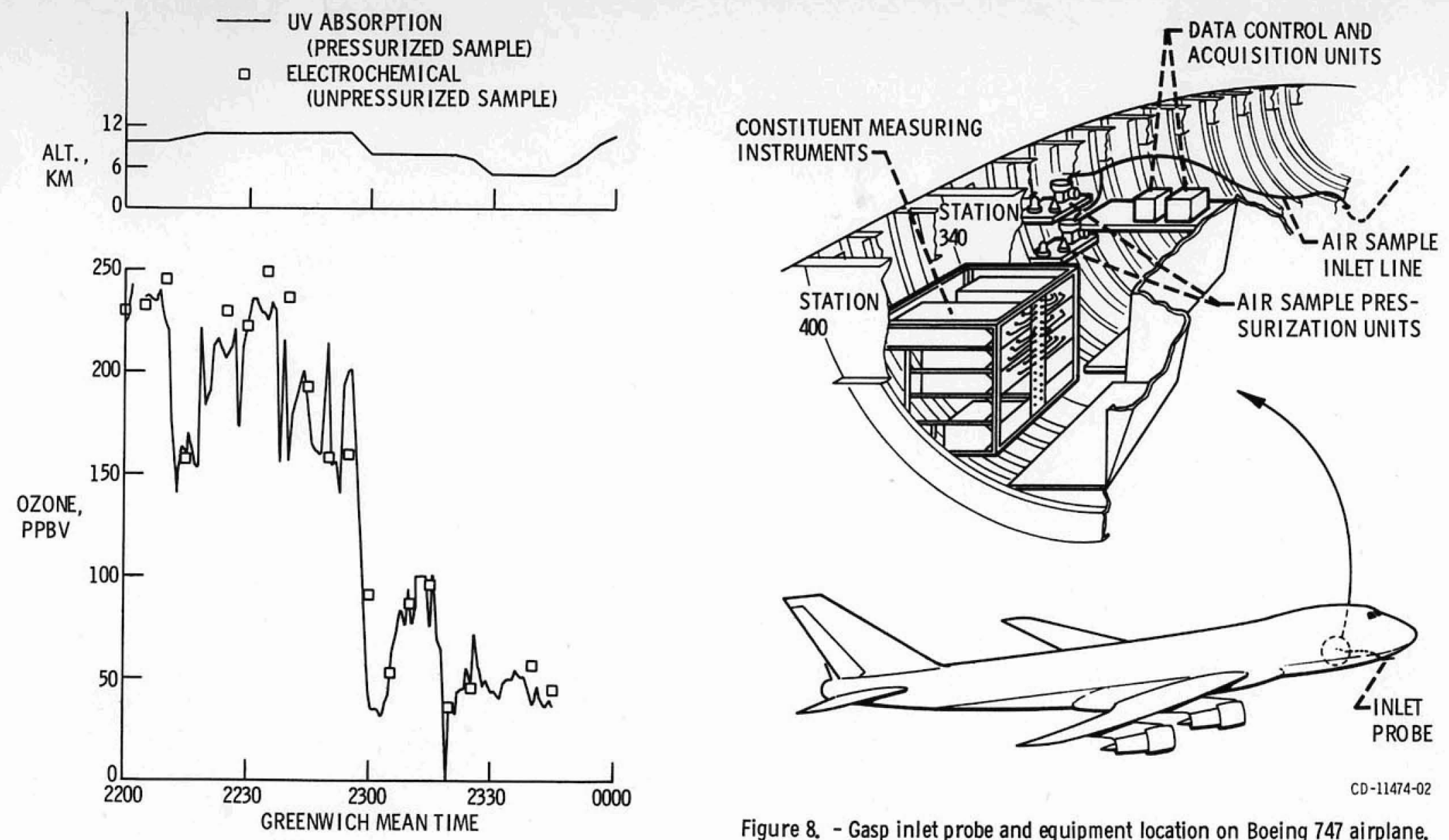

$C D-11474-02$

Figure 7. - Effect of pressurization on ozone measurements.

Figure 8. - Gasp inlet probe and equipment location on Boeing 747 airplane. 


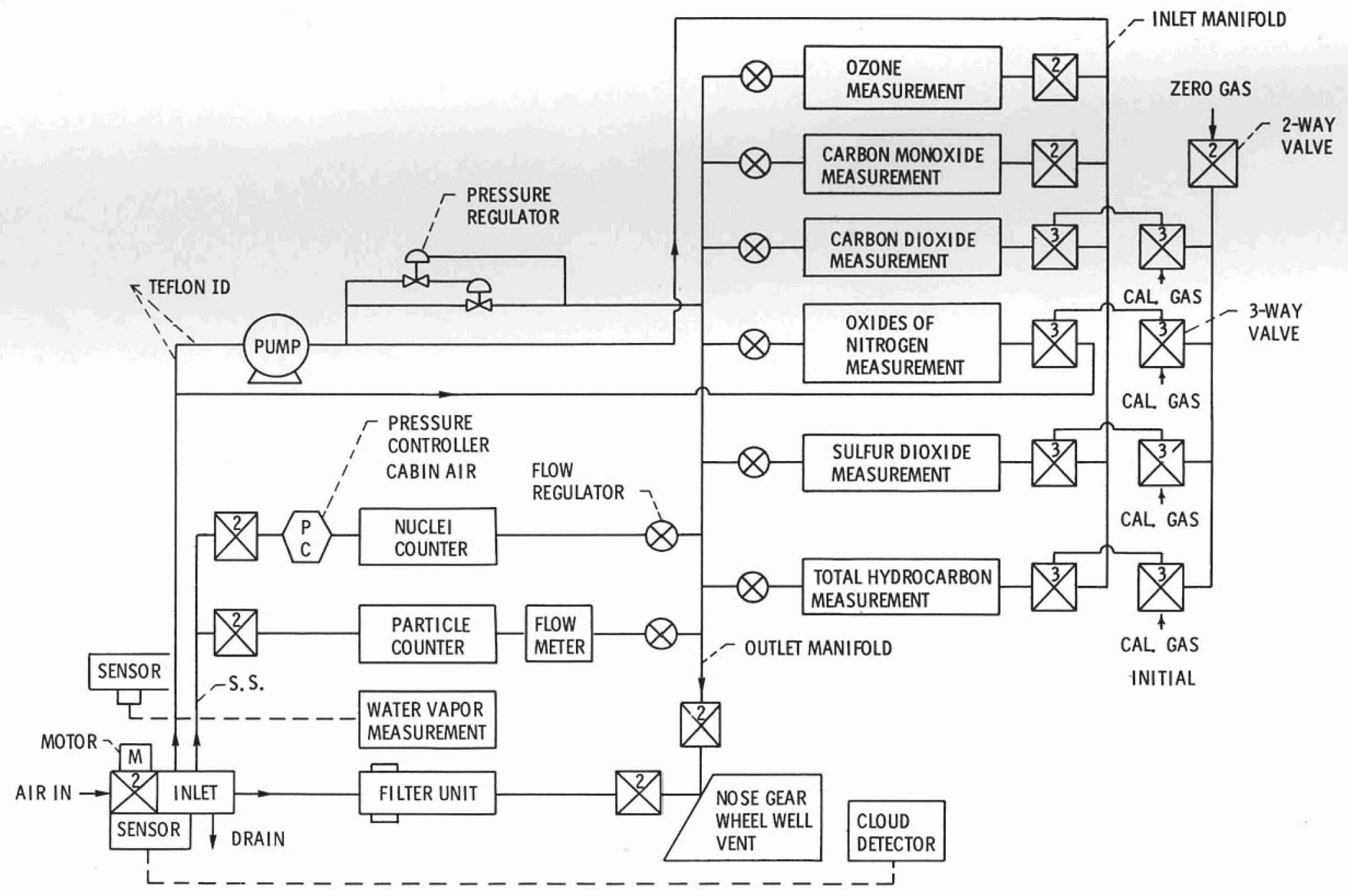

Figure 9. - Basic 747 air sample flow system. 


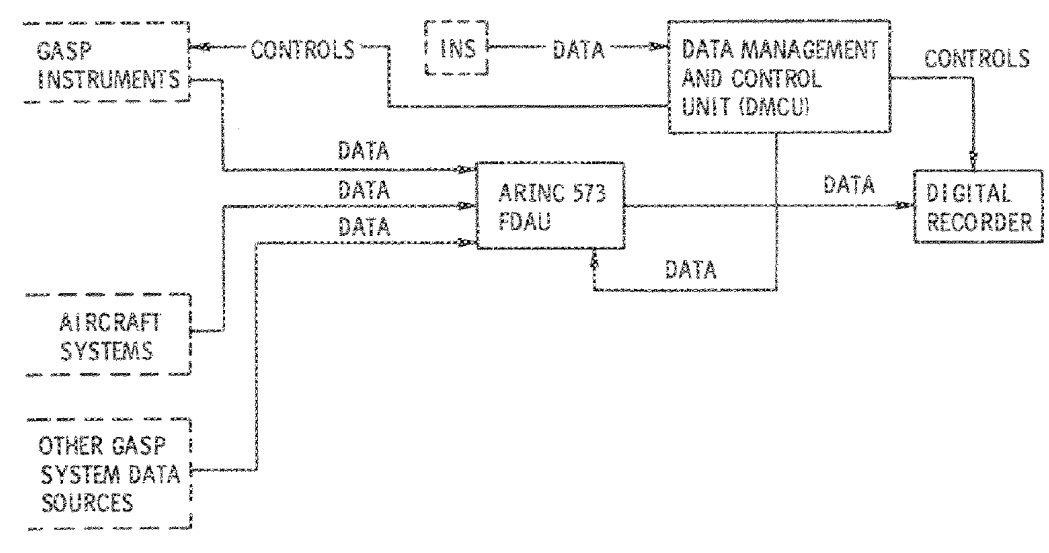

Figure 10, - Data acqusition, management, control, and recording system.

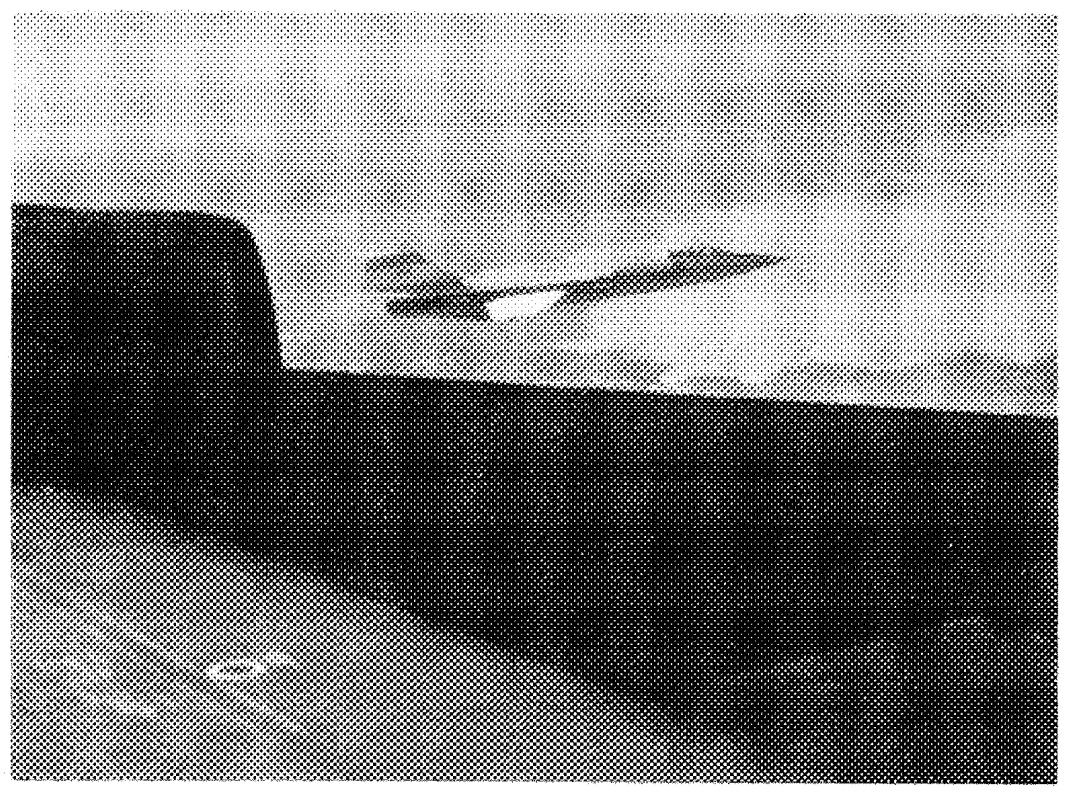

Tigure 11. - Rendezvous between F-104 and CV-990 airctat, 11 kilometer altitude, 0.8 Mach number. 


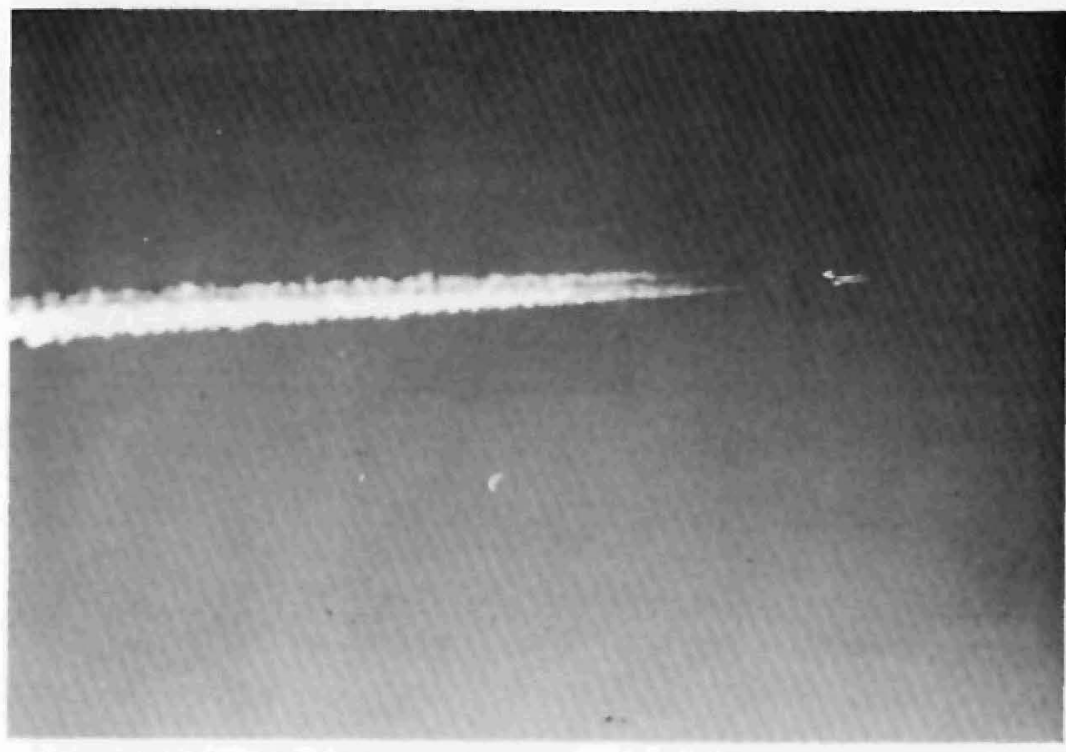

Figure 12. - F-104 aircraft contrail, 11 kilometer altitude, 0.8 Mach number.

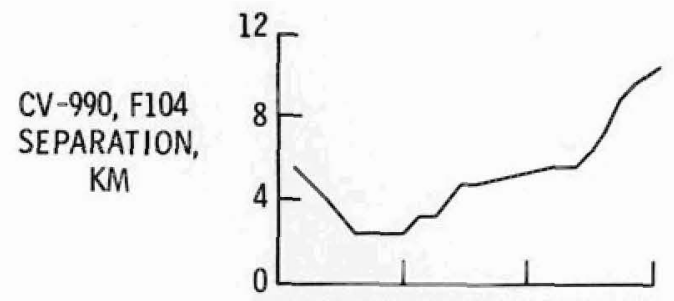

(a) SEPARATION DISTANCE

$\mathrm{CO}$, PPBV

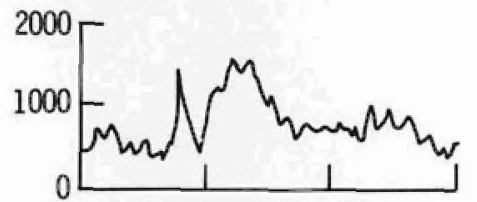

(b) CARBON MONOXIDE.

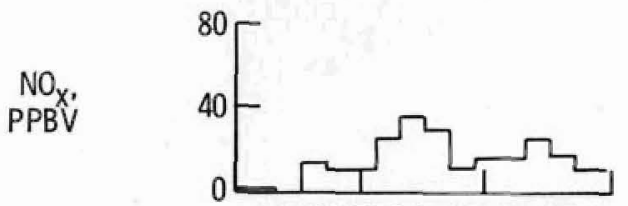

(c) OXIDES OF NITROGEN.

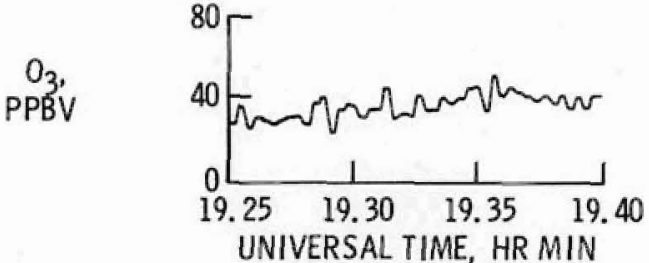

(d) OZONE.

Figure 13. - Measured concentrations in $\mathrm{Fl} 04$ wake, 11 kilometer altitude, 0.8 Mach number. Fl04 engine afterburner operating. 